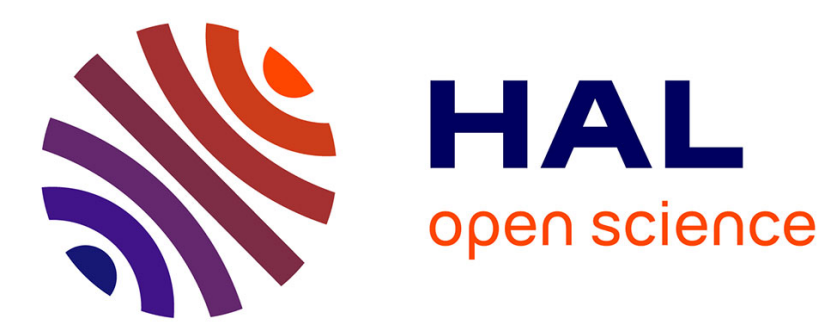

\title{
Characterization and local phenomenological model of Barkhausen noise under mechanical and magnetic excitations
}

\author{
B Gupta, Y Hebrard, J B Coudert, Benjamin Ducharne
}

\section{- To cite this version:}

B Gupta, Y Hebrard, J B Coudert, Benjamin Ducharne. Characterization and local phenomenological model of Barkhausen noise under mechanical and magnetic excitations. INTERMAG 2018 , Apr 2018, Singapore, Singapore. hal-01856307

\section{HAL Id: hal-01856307 https://hal.science/hal-01856307}

Submitted on 10 Aug 2018

HAL is a multi-disciplinary open access archive for the deposit and dissemination of scientific research documents, whether they are published or not. The documents may come from teaching and research institutions in France or abroad, or from public or private research centers.
L'archive ouverte pluridisciplinaire HAL, est destinée au dépôt et à la diffusion de documents scientifiques de niveau recherche, publiés ou non, émanant des établissements d'enseignement et de recherche français ou étrangers, des laboratoires publics ou privés. 


\title{
Characterization and local phenomenological model of Barkhausen noise under mechanical and magnetic excitations
}

\section{INTERMAG 2018 - GT 03 - 27/04/2018 - Hysteresis Modelling I}

\author{
B. Gupta, Y. Hebrard*, J.B. Coudert*, B. Ducharne
}

Laboratoire de Génie Electrique et Ferroélectricité - INSA de Lyon

Bât. Gustave FERRIE, 8 rue de la physique, 69621 Villeurbanne cedex, France

*SKF-Aerospace,

22 rue Brillat SAVARIN, 26958 VALENCE, France

Corresponding author: Ducharne B.

Benjamin.ducharne@insa-lyon.fr

Tél: +33(0)4 $72438833 \quad$ Fax: +33(0)4 72438874

\section{ABSTRACT}

Post-treatment and rescaling, it is possible to plot local hysteresis cycles from the measurement of local magnetic Barkhausen noise. If the material is homogeneous and if similar excitation conditions are imposed, the local hysteresis cycles obtained are comparable to the classical magnetic hysteresis cycles $B(H)$ (the cross-section magnetic average induction $B$ as a function of the surface tangential excitation field $H$ ). These local Barkhausen noise hysteresis cycles give interesting clues about the evolution of the microstructure of the magnetic material (internal stresses, level of degradation etc.). This makes it an indispensable tool for the nondestructive evaluation of ferromagnetic steels. In this paper, a phenomenological modeling of the Barkhausen noise from the local modeling of $B$ subjected to an excitation field $H$ and/or a uni-axial mechanical stress $T$ is proposed. The objective is to provide an absolute quantification of the internal residual stresses because of the Barkhausen noise measurements.

\section{KEYWORDS}

Barkhausen noise, magnetic hysteresis loop, model, hysteresis, mechanical stress. 


\section{MAIN TEXT}

The use of non-destructive micro-magnetic control techniques such as the measurement of magnetic Barkhausen noise has recently increased exponentially in the industrial environment. This renewed interest is mainly due to the improvement of analog and digital signal processing techniques that have allowed this quality control type to be integrated into the production lines in real time [1]. Micromagnetic techniques can be used to trace interesting properties of the tested samples (hardness, residual stresses, grinding burns etc.) [2]. Barkhausen noise owes its origin to the magnetization processes of a ferromagnetic material. It is established that a ferromagnetic material, even in a demagnetized state is magnetically divided into finite regions called as domains. Each domain is characterized by its own direction and orientation of magnetization. The process of magnetization consists of converting this multi-domain state into a single domain characterized by a direction and a sense of magnetization very close to the external magnetic field $H$ imposed on the material. This process is not continuous but consists of small discrete variations: jump from a pining defect (micro-structural obstacles like precipitation) to another defect of the domain walls (domains boundaries) [3]. This local variations of magnetization states are known as "Barkhausen event". These changes induce pulsed eddy currents near the moving domain walls that develop in all space directions. These abrupt changes in the magnetic structure through the material also induces local and rapid flux variations that can be easily measured using a dedicated local micro magnetic field sensor. In recent publications dealing with the topic, many authors define a new quantity called Magnetic Barkhausen energy $\left(M B N_{\text {energy }}\right)$ [4]. The $M B N_{\text {energy }}$ is obtained from the temporal integration of the square of the local magnetic field sensor voltage output (equation 1). This "post-treatment" technique can be used to trace a hysteresis cycle $M B N_{\text {energy }}(H)$ from the local measurement of magnetic Barkhausen noise. At low frequency, if the material is homogeneous and isotropic and after rescaling thanks to a coefficient $v$, the Barkhausen cycles obtained are very similar to the usual hysteresis cycles $B(H)$.

$$
M B N_{\text {energy }}(H)=v \cdot \int_{0}^{T} \operatorname{sign}\left(\frac{d H}{d t}\right) \cdot\left(V_{\text {Barkhausen }}\right)^{2} d t
$$


These observations confirm the microscopic origin (wall movements) of the magnetic hysteresis under low frequency excitation. In the extended version of the article, the numerical scheme will be described that is used to return the temporal Barkhausen noise envelope under both magnetic and uniaxial mechanical stress. This numerical scheme is based on both local magnetic hysteresis model and an inverse method linked to magnetic Barkhausen energy.
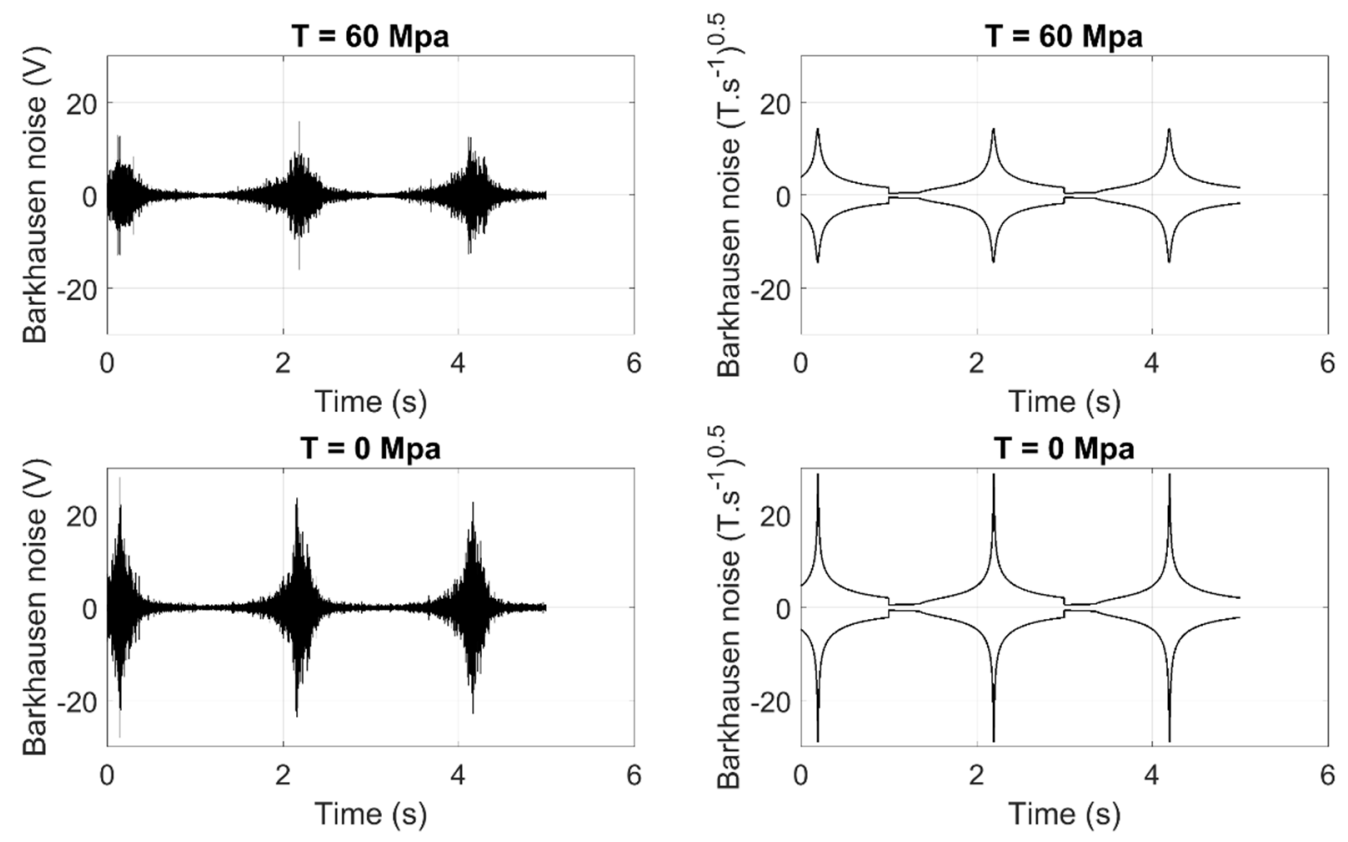

Figure 1. Magnetic Barkhausen noise (left) and simulated Barkhausen envelop under both magnetic and uniaxial mechanical stress excitations.

The good simulation results displayed in Fig. 1 are very promising. By correctly anticipating in simulation the material behavior, we will have access to some microstructural information (such as precipitations, local residual stresses). From a non-destructive evaluation point of view, this set of information will allow us to anticipate some failures and ageing issues.

\section{REFERENCES}

[1] W.A. Theiner, B. Reimringer, H. Kopp and M. Gessner, "3MA-Testing Equipment, Application, Possibilities and Experiences. Characterization of materials", (ed. by P. Höller, V. Hauk, G. Dobmann, C. Ruud, R. Green), Springer-Verlag Berlin, 1989.

[2] B. Gupta, B. Ducharne, G. Sebald, T. Uchimoto, A space discretized ferromagnetic model for non-destructive eddy current evaluation, Trans. on mag, 2017.

[3] T.W. Krause, J.A. Szpunar, D.L. Atherton, Anisotropic flux density dependence of Magnetic Barkhausen Noise in oriented 3\% Si-Fe steel Laminates, IEEE Trans. on Mag. 39,562-566, 2003.

[4] B. Ducharne, MQ. Le, G. Sebald, PJ. Cottinet, D. Guyomar, Y. Hebrard, "Characterization and modeling of magnetic domain wall dynamics using reconstituted hysteresis loops from Barkhausen noise”, J. of Mag. And Mag. Mat., pp. 231-238, 2017. 